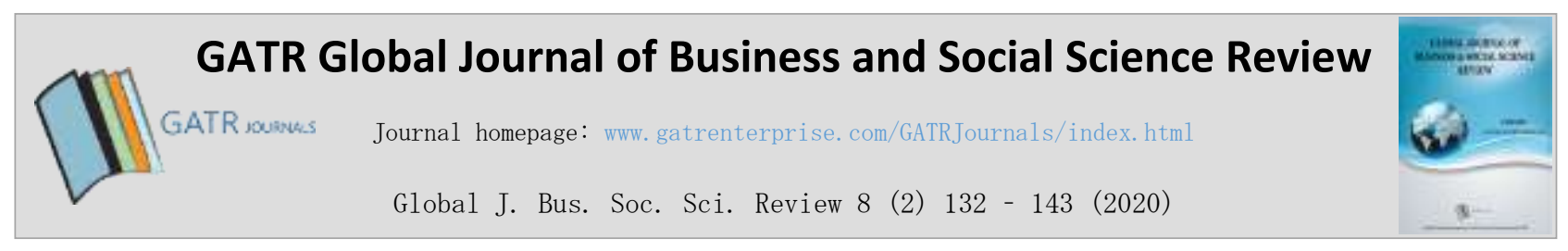

\title{
Educational Innovation Based on Assessment for Learning Concepts: A Guide to Drive Education 4.0
}

\author{
Natcha Mahapoonyanont ${ }^{1^{*}}$ \\ ${ }^{1}$ Thaksin University, Songkhla Campus, 90000, Songkhla, Thailand
}

\begin{abstract}
Objective - Education 4.0 originated from analysing Thailand's problems such as economic failure, political failure or social failure. Every problem involving failure blames education. Thailand 4.0 has a goal for Thailand to innovate. However, have education courses and teacher's education met the goals of Thailand 4.0 even though courses have been changed and modified for over 50 years? It is now time to change the country's education process to meet the country's innovation needs. Therefore, improving the quality of education management standards through school education systems is important because learning is driven by teachers and students in the classroom. Teachers need to manage various needs in classrooms, including social, emotional and pressure situations of an average of 30 or more students per classroom to help students learn and grow to become good learners in the future.

Methodology/Technique - The aforementioned education quality standards will be improved if teachers can operate effectively in the classroom. Consequently, the question is how the agencies and organizations involved can help teachers in this situation because the level of improvement in education quality is "dependent on teachers". This may seem unfair for this huge responsibility because part of product output is affected by input factors and the aforementioned mission should not be left as the duty of only teachers or education personnel.

Finding \& Novelty - The research findings suggest that all teachers develop their careers by using the concept of AFL and could help students to raise their achievement and also could be efficient guides to drive Education 4.0 for Thailand.

This research is aimed at studying and developing educational innovation based on assessment for learning to drive Education 4.0 and pilot study in the first phase by referring to teachers' observations, assessments, and recommendations.
\end{abstract}

Type of Paper: Empirical

JEL Classification: A00, A2

Keywords: Thailand 4.0; Assessment for Learning; Educational Innovation; Educational Reforms; Educational Quality.

Reference to this paper should be made as follows: Mahapoonyanont, N. (2020). Educational Innovation Based on Assessment for Learning Concepts: A Guide to Drive Education 4.0, Global J. Bus. Soc. Sci. Review, 8(2): 132 - 143. https://doi.org/10.35609/gjbssr.2020.8.2(7)

\section{Introduction}

Thailand 4.0 has been a national economic development model for no less than 50 years. In 1961, Thailand had its first National Economic and Social Development Plan.

\footnotetext{
${ }^{*}$ Paper Info: Revised: March 13, 2020

Accepted: June 4, 2020

* Corresponding author: Natcha Mahapoonyanont

E-mail: natcha@ scholar.tsu.ac.th

Affiliation: Thaksin University, Songkhla Campus, 90000, Songkhla, Thailand
} 
That era is the era of Thailand 1.0, agrarian society with a primary focus on agriculture for a considerable period. Next was the Thailand 2.0 era, with an emphasis on light industry. Most famous is the textile industry. Later on, Thailand entered the Thailand 3.0 era and headed toward more complex industries.

With the entry into the Thailand 4.0 era, Thailand needs to innovate without dependence on foreign countries. This asks a challenging question. How can we develop our innovations, even though we have plenty of resources nationwide? Therefore, each ministry has a slogan followed by 4.0.

The Ministry of Education has "Education 4.0" as a slogan (Jannoi, 2017). Improving the quality of education management standards through school education systems is important because learning is driven by teachers and students in the classroom. Teachers need to manage various needs (including social, emotional and pressure situations) for an average of 30 or more students per classroom in order to help students learn and grow to become good learners in the future. The aforementioned education quality standards will be improved if teachers can operate effectively in the classroom. Therefore, the question is how the agencies and organizations involved can help teachers in this situation because the level of improvement in education quality is "dependent on teachers".

This may seem an unfair responsibility as part of product output is affected by input factors and should not be left as the duty of only teachers or education personnel. The education system is currently showing interest and encouraging teachers, education supervisors and school administrators to implement concepts and practices regarding "Assessment for Learning (AFL)" in classrooms rather than emphasizing only "Assessment of Learning (AOL)" to meet the requirements of central education agencies (Naiyaphat, 2010).

Stiggins (2002) has suggested guidelines for raising the educational standards. He states that to increase learning achievements as much as possible, we need to pay more attention to the development of evaluation systems for the development of learning in classrooms, such as:

1) investing in formative assessment as well as summative assessment;

2) organizing long-term curriculum or innovation to support and develop teachers and administrators on AFL; and

3) enhancing the management process to ensure that teachers and administrators have the skills to measure and assess correctly both in terms of AFL and AOL.

Researchers agree with the second suggestion of Stiggins to create curricula, innovations or guidelines for teachers to encourage long term learning. This is probably the right choice for the current Thai education environment and is suitable for researchers and teachers in higher education institutions, and also the part of teacher production institutions.

This paper aims to describe the picture of educational innovation based on AFL concepts and to evaluate the results of the implementation of educational innovation based on AFL concepts. The researcher hopes that it should be able to achieve the concepts and goals of educational reform and education 4.0 in Thailand. The rest of this paper is organized as follows. A survey of related literature is provided in Section 2, Section 3 describes the research methodology, the results are reported in Section 4 and Section 5 concludes the paper.

\section{Literature Review}

\subsection{Thailand 4.0 and Education 4.0}

Jannoi (2017) made the following interesting presentation of Thailand 4.0 and Education 4.0 concepts:

"Thailand 4.0 is a national economic development model for no less than 50 years. In 1961, Thailand had the first National Economic and Social Development Plan. That era was Thailand 1.0, agrarian society with a 
primary focus on agriculture for a considerable period. Next is the Thailand 2.0 era with an emphasis on light industry. Most famous was the textile industry. Later, Thailand entered the Thailand 3.0 era and headed toward more complex industries. Many industrial estates were opened, and many foreigners made investments. Economic growth was at $7-8$ percent per year and natural gas was discovered. The entry into the Thailand 4.0 era is an entry into an era when Thailand needs to innovate without dependence on foreign countries. It is time for every sector to brainstorm and develop the country to become Thailand 4.0. Therefore, each ministry has a slogan followed by 4.0. The Ministry of Education has "Education 4.0" as a slogan."

Education 4.0 originated from analyzing Thailand's problems such as economic failure, political failure and social failure. Each problem involving failure was blamed on education. Thailand 4.0 has a goal for Thailand to innovate. However, have education courses and teacher's education met the goals of Thailand 4.0, even though courses have been changed and modified for over 50 years?

It is now time to change the country's education process to meet the country's innovation needs. The Ministry of Education must lead and move with schools that work directly according to the following content:

1) The Ministry must specify policies or issue ministerial regulations for the number of students per classroom to not exceed 36 students for true teaching efficiency;

2) School readiness must be equally prepared throughout the entire country, including every sub-district, district and province. Media, equipment, teachers, buildings and facilities must be equally prepared without creating a comparison of differences;

3) Courses must be improved, and courses such as computers and technology may become main subjects and not part of vocational subjects. Learning by subject has advantages as subjects can be changed every year to meet changing needs;

4) STEM subject education and active learning must be used to provide education in schools; and

5) Indicators must be created at the personal level for assessing teachers' performance and learn strengths and weaknesses. Teachers need to be improved individually (Jannoi, 2017).

\subsection{Characteristics of Thai Teachers in the Next Decade}

Sompongtam et. al. (2010) studied trends in the characteristics of Thai teachers in the next decade (2019). According to the findings, desirable characteristics for Thai teachers in the next decade (2019) are focused in 4 areas. These consist of professional knowledge and experience, personality, leadership in education development, and professional morals and ethics.

In the first area (professional knowledge and experience) teachers need to have professional ability in assessing situations based on reality. They must have the ability to create and use instruments in measuring and assessing achievements before and during learning and summarize learning achievements to make assessments based on real conditions. This includes intellectual, mental and skill assessment, assessments from work files and, assessment and judgment of students' learning.

\subsection{Assessment for Learning}

Traditionally, schools have used assessment based on the pending final exam, and therefore the threat of low or failing grades to motivate students. To maximize learning, our teachers believed in maximizing anxiety and intimidation to achieve results. The pressure to achieve high test scores and good grades, it had been believed, would motivate greater effort and thus more learning.

The recent change within the mission of colleges has clouded this traditional view of the connection between assessment and motivation. To examine how and why we must explore our assessment legacy and 
its motivational intricacies. As you may see, through that retrospective, we are going to discover a far more productive way for assessment to assist students to succeed. (Stiggins, 2005: 324)

Meanwhile, formative assessment has been the label used for assessing and promoting students' learning, not merely just for judging or grading. Within the past few years, formative assessment has emerged as an increasingly prominent tool for school improvement (Stiggins, 2005: 326). Studies by Black and Wiliam (1998) and Hattie (2009) confirm that formative assessment has a great impact on students' learning.

\subsection{Related Studies}

In the Thailand context, Mahapoonyanont et. al. (2017) suggest Assessment for Learning in Thailand needs to build assessment capacity right across its education system, and that teachers in Thailand wish to implement good formative assessment, they lack the necessary knowledge. Mahapoonyanont et. al. (2017) have developed the model to promote teachers' capacity in assessment for learning comprised five main components:

1) Professional Learning Community and Organization Context (Shared Vision, Caring Communities, Collaborative Teamwork, PLC's Leadership, Promotion Structure, and Career Advancement);

2) Learning and Professional Development (consisting of setting meaningful goals, action/authentic learning, reflection);

3) Teachers' capacity (self-efficacy, knowledge, capacity in AFL);

4) Student learning; and

5) Professional Development Evaluation.

Gotwals and Birmingham (2016) studied the development of the capacity to assess during learning and assessment for learning among candidates for the teaching profession. According to the findings, teachers with high skills in the area of assessment during learning or assessment for learning were found to have methods for learning management with an emphasis on students.

Sezen-Barrie and Kelly (2017) studied the facilitation of teacher's warnings regarding assessment for learning and challenge in working effectively based on the teacher's perception. According to the findings, an analysis of classroom discourse found teachers to have used three different cycles of assessment for learning. Teachers' reflections in the video case showed teachers were able to learn and watch responses in new times and models. This provided teachers with recommendations in assessment for learning. The researcher concluded teachers' views regarding the efficiency of assessment for learning were the most important issue, but teachers' views were usually overlooked, even though assessment for learning is part of effective classroom discourse.

Bradley et. al. (2016) found assessment during learning to have more effect of assessment after learning. According to the findings, students' attitude toward assessment during learning was found to be effective in closing the gap between teachers and students. Teachers recommended that, even though students cannot provide answers, teachers will help students to better understand students' learning situations. Therefore, assessment during learning was able to improve students' learning achievements when measurements were made to summarize learning results.

Granbom (2016) studied the effects of assessment for learning on biology learning achievements. This study shows assessment of learning helped students work better with higher scores on the topic of gene technology when compared to other topics. This is a success, providing feedback data for students in many situations. In providing and accepting recommendations from teachers or friends, students had many opportunities in reflecting and assessing their understanding. The findings concurred with Hattie (2009) who states that assessment of learning seems to be the most important factor in driving better learning.

Kafol et. al. (2015) studied assessment of learning and the roles of learning support by punishing or rewarding. The findings confirmed the importance of assessment of learning in successful students' 
perception that assessments should be by punishing or rewarding, rather than supporting students' learning. Participatory assessment supported students' learning by changing students' and teachers' roles in the learning process. Teachers' roles changed from presenting the knowledge to support conversation, i.e. from being an expert to being a lecturer. For students, assessment of learning is important in creating learning situations that support students to learn the learning process, and help students discover new learning methods. In the area of assessment of learning, students need to be responsible for learning and provide support in selfassessments, peer assessments, and positive responses to create an attitude of self-control for learning.

Tangkitwanit and Sasiwutiwat (2012: 1) made an interesting conclusion regarding the failure of Thailand's system for assessing education results. Failure was concluded to be caused by a flawed assessment system. School and teacher assessment had almost no connection to students' learning achievements while many burdens were placed on teachers, thereby causing teachers to be pulled from students. In the area of standardized tests, although the principle is to measure students' learning directly, test questions had quality problems, and had no systematic disclosure of schools' average test scores to the public. Therefore, the current assessment system is not connected to the creation of responsibility in providing education, which is at the heart of improving education quality.

Namuang (2010: 112-121) provides an interesting summary of educational measurement and in schools. He found that they do not understand accurate measurement and assessment methods, causing measurement and assessment guidelines to be inconsistent with expected learning achievements. Scoring criteria for each school is not equal, and teachers at some schools are unfair and give students too many points. This causes disparities when using test scores to compete for education at the university level along with difficulty in measuring outcomes in each education facility. This prevents students' scores from being used to make true decisions regarding students' abilities. Teachers had no knowledge and understanding of measurements and assessments based on real conditions.

Alkharusi (2010) studied a multi-level model of performance in the area of assessment for learning and students' perceptions regarding environments of assessment for learning. According to the findings, perceived self-efficacy was found to be positively correlated with the environments of assessment for learning and perception regarding the assessment environment with significance in line with the social understanding theory. Usually, when high-efficiency students are confronted with difficulty, they search for moderately challenging learning situations and recognize failure as a learning opportunity. All of this is consistent with environments in assessment for learning.

William (2004) studied teachers' development in the area of assessment for learning with effects on students' learning achievements with a group of 24 teachers and high school students over six months. According to the findings, assessment during learning was found to have an effect size of 0.32 on learning achievements.

Black and William (2001) state that, in improving education achievement standards, the government needs to emphasize teaching and learning processes above prioritizing education standards and goals or external testing. Education planning, including school inspections, should focus on classrooms (called "black boxes") such as teachers, rules, testing, and standards, etc., including situations related to the aforementioned factors such as the emphasis on how students learn. Burdens should not be placed solely on teachers.

Kruger ad DeNishi (1996) conducted a meta-analysis of 131 studies related to feedback data, which is a major instrument for assessment, with an effect size of 470. According to a study with 12,652 subjects, and measuring 23,663 scores, the mean effect size was found to be 0.38 . This indicates that feedback data influenced workability, particularly feedback data of accurate information.

Based on a review of related research, assessment during learning was found to have a high mean effect size. In the area of techniques used in assessment during learning, the provision of feedback data using guidance was found to have the highest mean effect size. 


\section{Research Methodology}

\subsection{Population and Samples Selected}

The population in this research consisted of teachers, students and school administrators in educational institutions in the southern region. The sample consisted of 9 voluntary teachers ( 9 classroom units), with 3 teachers from lower primary level (teaching Grade 1 - 3), 3 teachers from upper primary level (teaching Grade 4 - 6), and 3 teachers from Secondary level (teaching Grade 7 -12).

\subsection{Description of variables}

The independent variable was learning management using educational innovation based on AFL concepts. The dependent variables consisted of:

1) AFL competency of teachers as perceived by teachers;

2) results of comparison of student achievement before and after the trial; and

3) student satisfaction after learning through the activities under the concept of AFL (assess only primary and secondary students).

\subsection{Research Procedures}

The independent variable was learning management using educational innovation based on AFL concepts. The dependent variables consisted of:

1) AFL competency of teachers as perceived by teachers;

2) results of comparison of student achievement before and after the trial; and

3) student satisfaction after learning through the activities under the concept of AFL (assess only upper primary students and secondary students).

\subsection{Research Procedures}

In developing educational innovation based on the concept of assessment for learning to drive Education 4.0, the researcher has used taken the following steps:

1) Study external variables to survey the needs for developing educational innovations using the basic concept of assessment for learning to drive education 4.0. This step involves surveying needs regarding development of educational innovation by using the concept of assessment for learning to drive Education 4.0,

2) Develop Educational Innovation based on the Concept of Assessment for Learning. The researcher defines educational innovation as using the concept of assessment for learning to design and create a conceptual framework of educational innovation including studying documents systematically, analyzing and designing research instruments,

3) Pilot study for studying the feasibility of innovation, working together and having close interactions between the researcher and small groups of teachers, and

4) Reflect the findings from pilot studies, referring to teachers' observations, assessments, and recommendations. 


\section{Results}

\subsection{The need to develop educational innovations}

The needs to develop educational innovations based on the concept of assessment for learning to drive education 4.0 are divided to two dimensions. The first dimension is the Policy dimension:

1) teachers wish to implement good formative assessment, but lack the necessary knowledge, so we need training or innovation to support teachers working on assessment for learning. Teachers and school leaders need both a theoretical and a practical understanding of the learning and assessment processes;

2) we need to increase effective use of assessment in the classroom because formative assessments are above all a key pedagogical instrument in a teacher's toolbox; and

3) teachers should be able to move beyond superficial approaches to formative assessment and develop the skills required to provide students with detailed, timely and specific feedback on their performance. Shifting attention away from a teacher-centered approach and towards one that focuses on students themselves requires teachers to adapt their techniques to meet diverse learning needs and help students build their assessment skills to inform their future learning.

The second dimension is the Method dimension:

1) the strategy should focus not only on the content of the training but also on delivery methods that prioritize school-based, job-embedded learning opportunities whenever possible. This could involve mentoring, classroom observations, staff discussions, or joint planning focused on different aspects of the curriculum or the development of particular skills; and

2) teachers need to be trained (e.g. using workshops) before practicing in class. They also would like to practice authentic learning on the job under the supervision and observation of a coach, mentor or expert, together with their students.

\subsection{The development of educational innovation based on the concept of assessment for learning}

The researcher defined educational innovation based on the concept of assessment for learning by inviting teachers, supervisors, principals, academics from school and university, and service area offices. They were invited to a focus group and participated in picturing the perspective of educational innovation based on the concept of assessment for learning.

From the results of focus group, we found that suitable educational innovation based on the concept of assessment for learning in the Thailand context should be a module or handbook of assessment for learning. The system still will need a training workshop before practicing AFL in the classroom and should have coaching or mentoring by experts during authentic learning (practical in class).

Accordingly, the researcher has constructed a handbook of AFL and the procedure to enhance teachers' capacities with AFL. Course content is focused on the following four components and models for measuring and assessment for learning in the classroom:

1) Determination of learning and development guidelines,

2) Assessment of students' knowledge and understanding of learning goals, assignments and activities in course content which can be used to assess students' knowledge and assessment,

3) Feedback information, provision of explanations or recommendations for small groups to increase students' understanding of learning goals. This may include explanations of old knowledge or content, education media recommendations, and assignment of tasks and activities in course content to facilitate teaching in small groups, and 
4) Assessment after providing necessary feedback data for students' learning regarding students' ability to achieve learning achievements, recommendations and instruments for assessing students understanding.

\subsection{The procedure of pilot study of educational innovation}

The researcher has started this phase based on the model to promote teachers' capacity in assessment for learning which developed by Mahapoonyanont et. al. (2017) as shown in Figure 1:

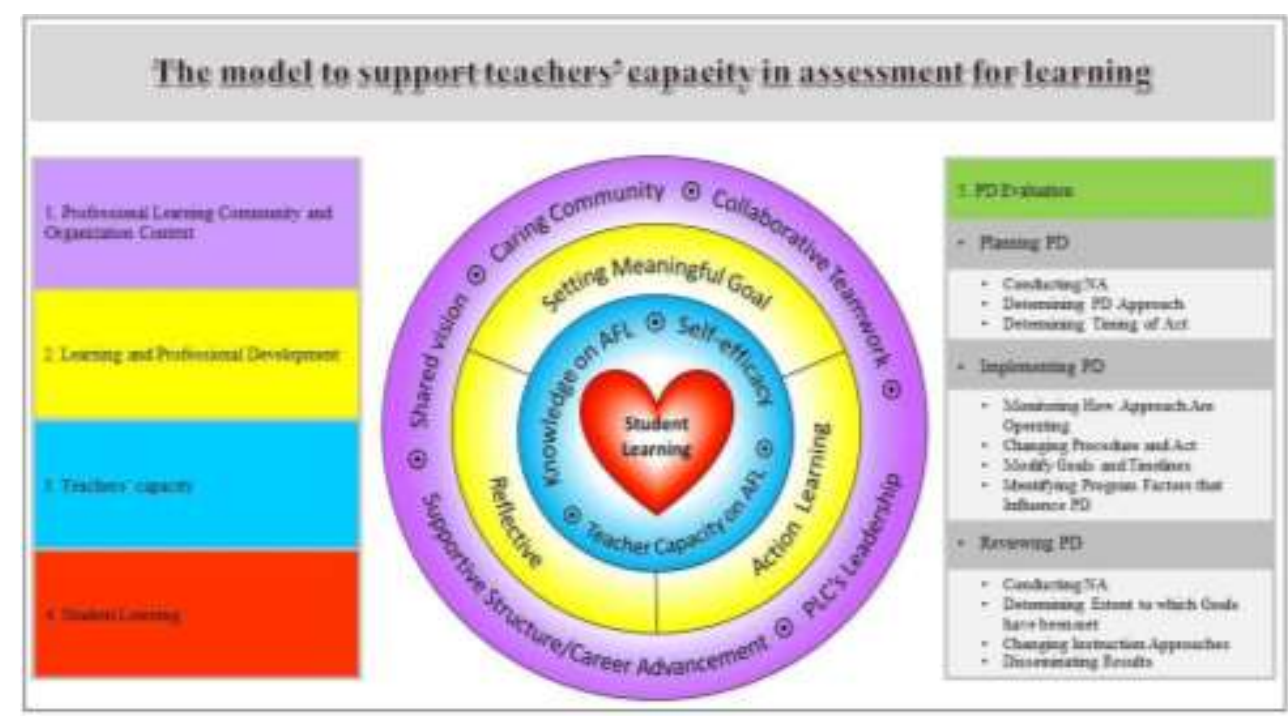

Figure 1. Model to promote teachers' capacity in assessment for learning

The procedure of a pilot study of educational innovation is shown in Figure 2

1. Make an understanding with the
principals of the sample school unit about
the elements of the whole model, and the
school should set the policy to support the
model.

2. Workshop to enhance teachers' capacity on Assessment for Learning about Knowledge, Self-efficacy, and Capacity on AFL (one day)

3. Learning and professional development under monitoring and coaching by experts and has a reflection on every Friday afternoon. (8 weeks)

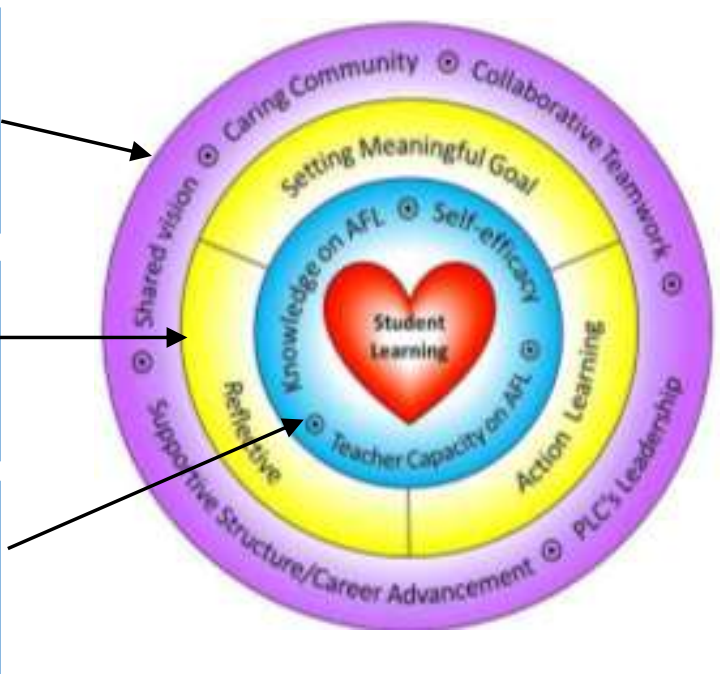

Figure 2. The procedure of pilot study of educational innovation 


\subsection{The findings from the pilot study}

From the result and reflection of the pilot study found that:

1) There was more engagement between teachers, students, parents, and principals.

2) The environment of the classroom has become more understanding and comfortable, with the relationship between students and with their teacher has become closer.

3) That by supporting self-directed students and teachers, they have better understood themselves, and could be direct themselves to move forward to reach the goals.

4) There are some significant statements from teachers and students as follows:

"I asked the children to write feedback after completing the exercises. When complete, I could divide the exercises into 4 divisions according to the level of understanding that the children rate. Everyone like the way what happened."

"We will know if any child does not understand or needs help, sometimes in our class, we don't have enough time to provide one to one attention. But, as the accuracy is not $100 \%$, we need to also look at the child's evaluation along with the real achievement."

"Another advantage is that I sent the self-feedback to the parent group to inform parents. Therefore, parents could open and read feedback to know what problems their children were having with their studies, which matters? We need to find a way to do more tutoring."

"It was as though the children had communicated with the teacher. He also communicated with parents, which is regarded as a follow up together. And is evidence of quality teaching and learning management by teachers and learners."

"The point is the ability to explore students' understanding of lessons, more feedback that resembles a teacher-student communication style in one-by-one teaching. When we know the problem, we can solve it later."

"There was a clear level of understanding, and they could help themselves learn more things to develop. Teachers and parents can better help to solve problems for students."

"The benefits of tools to teachers are:

1) easy to follow up on the learning management and student grades;

2) real-time feedback from students because it is a periodic assessment;

3) evidence that is empirical in terms of teaching and learning which can be used to communicate understanding between teachers, students and parents about the condition of teaching and learning; and

4) the tool is a stimulant for teaching and learning atmosphere and increasing classroom challenges."

\subsection{The evaluation result of educational innovation}

AFL competency of teachers according to the perception of the teachers themselves found that AFL competency of teachers has an average between $0.84-0.95$. The findings show that the results from early 
childhood students are lower than primary and secondary levels which might be because students are still unable to communicate or express themselves well.

\subsection{The results of comparison of student achievement before and after the trial}

The comparison of the learning achievement of each classroom unit in the experiment showed that every unit had higher achievement after the experiment at the .01 level of significance.

\subsection{Student satisfaction after learning through the activities under the concept of AFL}

Primary and secondary students had satisfaction scores after learning by learning activities under the concept of AFL between $4.32-4.76$, which is at a high to highest level.

\section{Conclusion}

Educational innovation based on the concept of assessment for learning from this study showed that it could be an efficiency innovation to raise students' achievement.

Educational innovation based on the concept of assessment for learning from this study consisted of an AFL handbook, Professional Development Module (with multidimensional methods such as demonstration, practice, feedback, etc.). It ran for 8 weeks in the classroom by demonstration in the first week and authentic learning by practicing from the second week to the 8th week with monitoring and coaching by an expert. The results show that there is change in a positive way in the classroom and the learning environment.

The research examined the link between Professional Development and teaching practices inside the classroom and the impact on students' learning (Barber \& Mourshed, 2007; Palmer et. al., 2016). Many of the various educational system reform initiatives have failed to deliver improvements because they have little effect on what happens inside the classroom (Abdullah \& Hissa, 2018). Educational innovation based on the concept of assessment for learning is focused on building the students' assessment skills. The innovation has many advantages, but still has disadvantages such as validity and reliability. Further research in the field of assessment for learning will be required to resolve validity and reliability issues.

In general, the results of the innovation assessment were at a high level, maybe due to in the process of developing an innovative model. The researcher has surveyed opinions from relevant parties at all levels. Regardless of the views of administrators, teachers, supervisors, and academics, studies of concepts, theories, relevant research results, (such as the duration of the PD, the format of the PD) and the evaluation of educational innovation, there should be a focus on the results (Changes at the classroom level and affecting student achievement) (Barber \& Mourshed, 2007; Palmer et. al., 2016; Abdullah \& Hissa, 2018).

The results of the AFL competency of teachers according to their perception, found that the AFL competency has a very high average. This may be due to their involvement in authentic learning throughout the whole period. The teachers worked closely with researchers and experts, and were also closely monitored, and we had reflections of learning together every week.

The results of comparison of the learning achievement before and after learning of each classroom unit in the experiment showed that every unit had high achievement after learning at the statistical significance of 0.01 level. This may be because learners were enthusiastic in learning, and the close interaction between teachers and students. Teachers and students have the same understanding of the level of learning outcomes of each learner, there are some example statements from teachers as follows:

"I asked the children to write feedback after completing the exercises. When complete, I could divide the exercises into 4 divisions according to the level of understanding that the children rate. Everyone like the way what happened." 
"We will know if any child does not understand or needs help, sometimes in our class, we don't have enough time to provide one to one attention."

"Another advantage is to inform parents so that they can receive feedback to know what problems their children are having, and which subjects need additional tutoring. It's as though the children are communicating with the teacher, teachers communicate with parents, who can follow-up together. This provides evidence of teaching, learning, and the quality of teachers and learners. "

\section{Acknowledgements}

This work is supported by the Thaksin University Research Fund.

\section{References}

Abu-Tineh, A. M., \& Sadiq, H. M. (2018). Characteristics and models of effective professional development: the case of school teachers in Qatar. Professional Development in Education, 44(2), 311-322. https://doi.org/10.1080/19415257.2017.1306788

Alkharusi, H. (2010). A multilevel linear model of teachers' assessment practices and students' perceptions of the classroom assessment environment. Procedia-Social and Behavioral Sciences, 5, 5-11. https://doi.org/10.1016/j.sbspro.2010.07.041

Barber, M., \& Mourshed, M. (2007). How the world's best-performing school systems come out on top. New York: McKinsey \& Co. https://www.mckinsey.com/industries/social-sector/our-insights/how-the-worlds-best-performingschool-systems-come-out-on-top\#

Black, P., \& Wiliam, D. (2005). Inside the black box: Raising standards through classroom assessment. Granada Learning. https://doi.org/10.1177/003172171009200119

Black, P., \& Wiliam, D. (2001). Inside the black box: Raising standards through classroom assessment. Northumberland LEA. http://www.wyoaac.org/Lit/Inside\%20the\%20Black\%20Box\%20-\%20Black.pdf

Assessment, F. (2005). Formative Assessment Improving Learning in Secondary Classrooms Centre for Educational Research and Innovation. https://doi.org/10.1787/9789264007413-en

Grosas, A. B., Raju, S. R., Schuett, B. S., Chuck, J. A., \& Millar, T. J. (2016). Determining if active learning through a formative assessment process translates to better performance in summative assessment. Studies in Higher Education, 41(9), 1595-1611. https://doi.org/10.1080/03075079.2014.988704

Granbom, M. (2016). Formative assessment and increased student involvement increase grades in an upper secondary school biology course. Journal of Biological Education, 50(2), 185-195. https://doi.org/10.1080/00219266.2015.1028572

Hattie, J. A. C., \& Learning, V. (2009). A synthesis of over 800 meta-analyses relating to achievement. New York. Henning, H., \& Keune, M. (2007). Levels of modelling competencies. In Modelling and applications in mathematics education (pp. 225-232). Springer, Boston, MA. https://link.springer.com/chapter/10.1007/978-0-387-29822-1_23

Jannoi, P. (2017). Education 4.0. Special Article in MRG online. https://mgronline.com/ qol/detail/9600000025195

Kafol, B. S., Kordeš, U. and Brunauer, A. H. (2015). Assessment for learning in music education in the Slovenian context - from punishment or reward to support. Music Education Research, 19 (1), 17-28

Kluger, A. N., \& DeNisi, A. (1996). The effects of feedback interventions on performance: A historical review, a metaanalysis, and a preliminary feedback intervention theory. Psychological bulletin, 119(2), 254. https://psycnet.apa.org/buy/1996-02773-003

Mahapoonyanont, N., Hansen, S., \& Poskitt, J. (2017). A comparative study of model to support teachers' capacity in assessment for learning in Thailand and New https://www.researchgate.net/publication/320033912_A_Comparative_Study_of_Model_to_Support_Teachers'_Capacit y_in_Assessment_for_Learning_in_Thailand_and_New_Zealand

Mahapoonyanont, N., Hansen, S., \& Poskitt, J. Model to Promote Teachers' Capacity in Assessment for Learning. https://www.researchgate.net/profile/Natcha_Mahapoonyanont/publication/320225043_Model_to_Promote_Teachers' Capacity_in_Assessment_for_Learning/links/59d5db1 eaca2725954c789ff/Model-to-Promote-Teachers-Capacity-inAssessment-for-Learning.pdf 
Naiyaphat, O. (2553). Assessment in Classroom: Evolution and new concepts of Assessment for Learning. Srinakharinwirot Journal of Research and Development (Humanities and Social Sciences). 2(3), 1-12.

Namuang, A. (2010). Educational reform in Thailand. Princess of Naradhiwas University Journal, 2(2), $112-121$. https://www.academia.edu/4530814/Education_Reform_in_Thailand

Palmer, D. J., Sadiq, H. M., Lynch, P., Parker, D., Viruru, R., Knight, S., ... \& Stillisano, J. (2016). A classroom observational study of Qatar's independent schools: Instruction and school reform. The journal of educational research, 109(4), 413-423. https://doi.org/10.1080/00220671.2014.979908

Van den Berg, M., Harskamp, E. G., \& Suhre, C. J. M. (2016). Developing classroom formative assessment in Dutch primary mathematics education. Educational Studies, 42(4), 305-322. https://doi.org/10.1080/03055698.2016.1193475

Sezen-Barrie, A., \& Kelly, G. J. (2017). From the teacher's eyes: facilitating teachers noticings on informal formative assessments (IFAs) and exploring the challenges to effective implementation. International Journal of Science Education, 39(2), 181-212. https://doi.org/10.1080/09500693.2016.1274921

Somphongtham, J, Anannavi, P. and Khonchalard, K. (2010). A study of trends and characteristics of Thai teachers in the next decade (2019). Bangkok: Secretariat of the Teachers Council of Thailand.

Tangkitwanit, S. and Sasiwutiwat, S. (2012). Failure of the Thai Educational Evaluation System: Causes and Recommendations. Thai Post newspaper. Retrieve from https://thaipublica.org/2012/02/failure-thai-educational-system/ Stiggins, R. J. (2002). Assessment Crisis: The Absence of Assessment for Learning. Phi Delta Kappan. 83(10), 758765.

Stiggins, R. J. (2002). Assessment crisis: The absence of assessment for learning. Phi Delta Kappan, 83(10), 758-765. https://doi.org/10.1177/003172170208301010

Wiliam, D., Lee, C., Harrison, C., \& Black, P. (2010). Teachers developing assessment for learning: Impact on student achievement. Assessment in education: principles, policy \& practice. https://www.tandfonline.com/doi/full/\%2010.1080/0969594042000208994

Wiliam, D., \& Thompson, M. (2008). Integrating assessment with learning: What will it take to make it work? Routledge. 10.4324/9781315086545 